\title{
Research Supervision Team: Structures, Responsibilities and the Collaborative Roles for supporting Interdisciplinary Research
}

\author{
Santhi KUMARAN ${ }^{1,{ }^{*},}$, Nelson iJumba ${ }^{2}$ and Senthil KUMARAN ${ }^{1}$ \\ ${ }^{1}$ University of Rwanda, College of Science \&Technology, Kigali, Rwanda \\ ${ }^{2}$ University of Rwanda, Kigali, Rwanda \\ ${ }^{*}$ Corresponding author
}

Keywords: STEM, Interdisciplinary Research, RIP Model, Research Supervision Team (RST).

\begin{abstract}
Generally, they say that Universities must produce true knowledge and are centers of excellence for research, and it is the private sector that creates the wealth of a nation through the commercial exploitation of the research. But, this has been changed in today's University context. Universities are supposed to train students to be job creators and not job seekers by the translation of an innovative research finding into new products and industrial processes for socio-economic development. Therefore, in Science, Technology, Engineering and Mathematics (STEM) Applied Research (which can be Interdisciplinary or Multidisciplinary), Supervison, the supervisor's job is not only to educate doctoral students to possess knowledge but also to use the knowledge and create economic growth and welfare. As proposed by Relational, Intellectual and Physical RIP Model the diverse nature of STEM Applied PhD research will be handled by the Research Supervision Team (RST) approach. Though RIP model supports RST approach in which sharing supervision between several supervisors with different competencies, an individual supervisor should also possess skills to play multiple roles satisfying the academic demand and the market demand as nowadays most $\mathrm{PhD}$ students are linked to a project and financed by external sources, thereby introducing more market driven agendas. This paper discusses on the multiple roles of supervisors, types of collaboration, collaboration between roles and best approaches to ensure collaboration.
\end{abstract}

\section{Introduction}

Nowadays, at Universities new collaborations, such as science parks, research shared between Universities and Companies and University staff working as consultants are seen most. Supervision is an important task for the smooth running of doctoral research and training. Especially in STEM Applied Research (Interdisciplinary or Multidiciplinary) Supervision the traditional dyadic model of supervision, which conceives supervision as based around a one-on-one relationship between a student and a principal supervisor has to be displaced to a Relational, Intellectual and Physical (RIP) Space Model as discussed in [1] and shown in Figure 1 below.

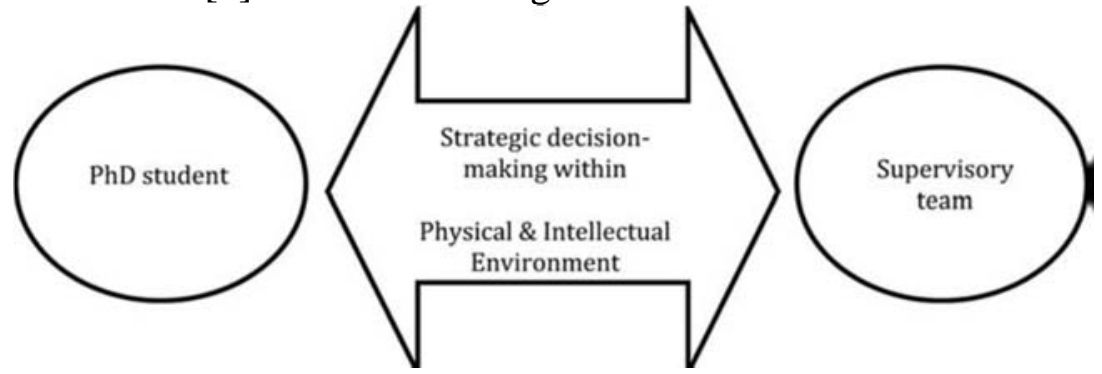

Figure 1. RIP Model

In RIP Model, a team supervision approach as discussed in [2] is emphasized. In the sense of doctoral programmes having two or more supervisors each of which offer substantial, sustained and relatively independent contributions to the research programme. The RIP model has been again revised to a RIPE model considering the Emotional space in PhD supervision as discussed in [3]. It is highlighted by Claire et all, that doctoral supervision is one type of human resource development relationship in higher education (HE), and that this relationship may be close or distanced, and 
involve technical and social support. Supervision can also be considered as Supervisors Learning process and experiencing Supervision as a self-learning: Promoting the supervisor's development, Imparting academic expertise, Upholding academic standards, Promoting learning to research, Drawing upon student expertise, Enabling student development, Venturing into unexplored territory, Forming productive communities, and Contributing to society as discussed in [4] by Christine et all.

In the following sections, the responsibilities of the various team members of the Research Supervisory Team are highlighted and their Collaborations and Problems faced will be discussed.

\section{Roles of the Research Supervisory Team (RST) members}

In order to adapt to the changing role of Universities, individual supervisor has to play multiple roles based on the students registered under him. In this model a student has more than one supervisor. One among the supervisors shall be designated as the main supervisor. Others can take the role of the co-supervisor(s) or advisors and will vary according to the research project. The different advisors and their role can be of the following nature:

(i) Main Supervisor: The individual who has the primary responsibility for supervision and the RST Chair. Along with the RST lead the students to the successful completion of a doctoral level Research.

(ii) Co-supervisor: Co-supervisors assist the Main Supervisors in guiding the $\mathrm{PhD}$ candidates. In many cases the co-supervisor will play a major role in directing the research and do have a responsibility for the student's progress, and will be expected to take an active role in the supervision process. They should be qualified to act as a supervisor, and share responsibility for the supervision.

(iii) Joint/Lead Supervisor: This is permitted where it is a joint $\mathrm{PhD}$ or other collaborative programmes. In such cases one of the supervisors from either host Institution or the Partner Institution should be designated as the Lead supervisor in accordance with the requirements of the particular joint or collaborative programme.

(iv) Assistant Supervisor: An individual such as a postdoctoral research associate who plays a significant role in the supervision process but does not have formal responsibilities for the supervision.

(v) Industry Supervisor: Nowadays in the field of Engineering, Research is conducted in collaboration with other partner organisations like Industries on collaborative projects. Elena in [5] analyzes university-industry collaboration focus on technological development.

(v) Non-Academic Supervisors: These can be Mentors, Project Managers etc

\section{Collaboration between Roles}

As per the RIP Model, the RST would comprise of all the above advisors are some of the above. It is essential that a collaboration agreement be put in place from the outset to ensure that all parties are aware of their role and responsibility in relation to the $\mathrm{PhD}$ project. The supervisor, possibly supported by one or more co-supervisors and the Doctoral committee are the people responsible for supervising and supporting the $\mathrm{PhD}$ researcher.

\section{Types of collaborations expected}

$>$ Type and extent of feedback from different Roles of Supervision- level of criticism and challenge expected.

$>$ Which areas of the project require which category of Supervisor and what level of supervisor intervention?

$>$ Formal/informal meetings between different advisors/ supervisors of the Project Supervision Team.

$>$ How often / in which situations will feedback regarding the progress and quality of work of the Student be given by the Research Supervision Team?

$>$ Level of different supervisor involvement during the project period and supervisor input. 


\section{Best Approaches to be Considered to Ensure Collaborations between the RST Members [6]}

a) Set up a Doctoral committee for each research student comprising of the advisors who are playing various supervisory roles in the Research Project. This ensures all parties are engaged in the project.

b) Ensure there is the necessary supervision at the Host University and at other Partner Institutions. Regular formal and informal contact moments between the $\mathrm{PhD}$ researcher, the (co)supervisor and/or the supervisory team are needed for good supervision.

c) Build a work plan. The contact moments between the PhD researcher and the (co)supervisor are laid down in the work agreements made during the annual performance reviews.

d) Ensure there is a balance between academic and non-academic demands.

e) Ensure there is a clear management structure.

f) Ensure the non-academic supervisor has also the authority to make decisions.

g) Conduct regular Doctoral Committee meetings and Progress reporting. They make sure that the doctoral process is being correctly followed and that the supervisory and final examination committees contain the right mix of individuals.

h) Ensure that relationships are maintained. The role of the supervisors and their relationships with their students are of critical importance and it is accepted that a wide range of successful student-supervisor relationships will exist. Given the central role that the relationship between supervisor and graduate student plays, focusing on the relationship early on contributes greatly to the successful completion of the graduate program. Various types of developing relationships are discussed in [7].

\section{Pros and Cons of having a RST}

a) Normally a Professor/ Associate Professor would be supervisors and usually they have tons of other responsibilities, both good (like supervising other students, giving lectures and visiting conferences for delivering keynote speeches and presenting their research results) and evil (like attending meetings and filling in forms). So, it is important to have cosupervisors so that no PhD students are left on their own for too long.

b) It is often good practice for there to be cosupervisors for every student, as it provides back up for those situations where one supervisor is ill, leaves or falls out with the student.

c) Sometimes the number of students supervised by an individual who is a Main Supervisor at any one time may be high than the normal satisfactorily limit. In such cases Co-supervisors could be of great support.

d) In some cases the supervisors can depart to other institutions. In such situations either the students will follow the supervisor if the Research is still in immature state or can stay with the host institution based on the Research work completion and the co-supervisors involvement.

e) In situations where a supervisor is granted an extended absence from college (eg sabbatical leave) or has extended sick leave, arrangements co-supervisors /other advisors can support the Research student to continue with his work.

f) In case the research is in collaboration with an Industry then there can be an Industry supervisor. Should the Industry expert possess a doctoral degree to be a supervisor OR it is sufficient for an Industry supervisor to have acquired sufficient and appropriate industry research experience? This is sometimes a challenging query raised.

\section{Multifaceted Role of an Individual Supervisor}

Moreover, as the old fashioned virtues of training $\mathrm{PhD}$ students for academic contribution and professional passion have been transformed these days in to a market driven research for economic development, an individual supervisor should possess various capabilities to play a multifaceted role in PhD supervision. 
It is well known that supervisor's job is not only to educate $\mathrm{PhD}$ students to possess knowledge but also to use the knowledge and create economic growth and welfare. This is being analyzed in paper [8]. Nowadays, PhD research work have become increasingly more diverse, can be fully financed by University, and wholly are partly financed by the industry, or by scholarships and own funds as given in [9]. Though, the diverse nature of PhD projects will be handled by the Research Supervision Team (RST) approach as proposed by the RIP Model. But, in order to adapt to the changing role of Universities, individual supervisor has to play multiple roles based on the students registered under him. An individual Supervisor have to be an academic Main supervisor for a student registered under him, but for another student under a project scholarship he has to be a Lead Supervisor, then for a student under industry collaborative research he should be act as a Consultant or Industry supervisor. The individual supervisor should have several facets based on the student registered. Therefore, an individual involved in supervision should be flexible and represent a wide professional spectrum to adapt to the changing University concept which follows the pipeline: Fundamental research $\rightarrow$ Applied Research (Interdisciplinary/Multidisciplinary) $\rightarrow$ Innovative Research $\rightarrow$ commercializing the research finding to products \& services and also to accommodate the diverse nature of $\mathrm{PhD}$ students/Projects registered.

\section{Conclusions}

It is evident that Research Supervisory Team (RST) proposed by the RIP Model is necessary to support both Interdisciplinary / Multidisciplinary Applied Research in the field of STEM. Based on the analysis, though RIP model supports a RST approach in which sharing supervision between several supervisors with different competencies, this paper emphasizes that an individual supervisor should also possess skills to play multiple roles satisfying the academic demand and the market demand as nowadays most $\mathrm{PhD}$ students are linked to a project and financed by external sources, thereby introducing more market driven agendas. Moreover, the active contribution of the Research Supervision Team and its effective collaboration plays an important role in forming the completion context that includes management of relational, intellectual, physical and emotional spaces that falls within the extensive $\mathrm{PhD}$ process of the researcher. The analysis presented in this paper shows that the Pros outweigh the Cons of having a RST, which is based on the RIPE model.

\section{References}

[1] Pam Green and John Bowden, "Completion mindsets and contexts in doctoral supervision Swinburne Research”, page 66-80, (2003), [Online] Available: www.emeraldinsight.com/09684883.htm

[2] Cally Guerina \& Ian Greena, “They're the bosses’: feedback in team Supervision”, Journal of Further and Higher Education, (2013), [Online] Available: http://www.tandfonline.com/loi/cjfh20

[3] Clair Doloriert and Sally Sambrook, Jim Stewart, "Power and emotion in doctoral supervision: implications for HRD”, (2012), [Online] Available: www.emeraldinsight.com/2046-9012.htm

[4] Christine Bruce \& Ian Stoodley, "Experiencing higher degree research supervision as teaching”, Studies in Higher Education, (2011), [Online] Available: http://www.tandfonline.com/loi/cshe20

[5] Elena Zukauskaite, “Innovation in cultural industries: The role of university links”, Innovation: Management, policy \& practice, Volume 14, Issue (3): 404-415, (2012)

[6] ESRC, "Good Practice Guidelines for Managing and Monitoring Collaborative Studentships", [Online] Available: www.esrc.ac.uk/funding-and-guidance/postgraduates/dtc/studentcollaboration/developing/index.aspx

[7] Catherine Chiappetta-Swanson, Susan Watt, "Good Practice in the Supervision \& Mentoring of Postgraduate Students”, McMaster University, (2011). 
[8] Pia Bøgelund, "How Supervisors Perceive PhD Supervision - And How They Practice It", International Journal of Doctoral Studies Volume 10, pp 39-55, (2015), [Online] Available: http://ijds.org/Volume10/IJDSv10p039-055Bogelund0714.pdf

[9] Forsknings- og Innovationsstyrelsen, "Evaluering af forskerkarriereveje- håndtering af forskeres karrierer på de danske universiteter [Evaluation of research career ways - Handling of researchers' careers at Danish universities]”, København: Forsknings- og Innovationsstyrelsen, (2011).

[10] Vicki L. Bakera; Lisa R. Lattucab, "Developmental networks and learning: toward an interdisciplinary perspective on identity development during doctoral study”, Department of Economics and Management, Albion College, Michigan, USA, Center for the Study of Higher Education, Pennsylvania State University, Pennsylvania, USA, 15 September (2010), [Online] Available: http://www.informaworld.com/smpp/title content=t713445574

[11]Christian Begin, Laetitia Gerard, "The Role of Supervisors in light of the experience of Doctoral Students”, Policy Futures in Education, Volume 11, no3, (2013), [Online] Available: www.wwwords.co.uk/PFIE 